\title{
Driving the Internet: Mobile Internets, Cars, and the Social
}

\section{Gerard Goggin}

Department of Media and Communications, The University of Sydney, Holme Building (Ao9a), Sydney NSW 2006, Australia; E-Mail: gerard.goggin@sydney.edu.au; Tel.: +61-2-9114-1218

Received: 22 December 2011; in revised form: 7 March 2012 / Accepted: 14 March 2012 /

Published: 20 March 2012

\begin{abstract}
This paper looks at the tandem technologies of cars and the Internet, and the new ways that they are assembling the social with the mobile Internet. My argument is two-fold: firstly, the advent of mobile Internet in cars brings together new, widely divergent trajectories of Internet; secondly, such developments have social implications that vary widely depending on whether or not we recognize the broader technological systems and infrastructures, media practices, flows, and mobilities in which vehicular mobile Internets are being created.
\end{abstract}

Keywords: mobile Internet; automobile; cars; Internet; mobile media; social transformations

\section{Introduction}

Contemporary "global cities", and cities in general, remain primarily rooted in and defined by automobility as much as by newer technologies. Thus, to understand the ways in which social life might be reconfigured by new technologies of information and communication will require that social analysts take seriously their relation to the car.-Mimi Sheller and John Urry [1].

Until recent times, it has been relatively uncommon to see the Internet and its futures bound up with cars. Now the automobile is emerging as an important site for the Internet, especially due to the resurgence of mobile Internet. This occurs at a time when the social functions of both the Internet and vehicles are experiencing important transformations.

In countries of the global north (an imprecise but still useful term), automobile culture is well entrenched, and continuing to grow in variety of meanings and uses attached to vehicles. On the production side, the technical sophistication of cars-especially with digital technologies and computerizations - continues to deepen. There are new possibilities for consumption activities in cars 
for drivers and passengers, but also in other connected spheres of the overall system of transportation and mobility. As new technologies have been progressively deployed in automobiles since the late twentieth century, the distinctive cultural forms of cars (often called "automobility") have become richer, generating closely related and complex systems of media and communication in their own right. The experience of interacting with cars as driver, passenger, pedestrian, or recipient of people and goods they convey has become much more experience. The driving of cars relies upon a range of information and communication technologies, as does riding in them. Over and above these in-car technological systems, and wider vehicular, transportational, and navigational systems in which they are set, we can point to the deepening incorporation of the car into home entertainment, media and communication ecologies as well as public spheres.

From the side of the Internet, there are a number of key developments. The Internet has reached significant levels of use globally — with the expectation in many societies that it is readily if not always available ("on"). The social implications of this phase of densely, often connected phase of the Internet are still being debated [2-5]. Since 2005 mobile Internet has become widely useful for a number of reasons: availability of mobile and wireless networks with greater data transfer rates; improvements in Internet browsing and email on mobiles; advanced multimedia handsets (especially the vogue for "smartphones" since the launch of the iPhone); the renaissance of mobile computing and software evident in the popularity of "apps"; the rise of mobile broadband; the takeup of social networking and social media platforms on mobile devices; the emergence of the tablet computer; and the emergence of locative, mobile media. At best, mobile Internet is a portmanteau term-what we are really experiencing is a plurality of mobile Internets [6]. Nonetheless as mobile Internet becomes pervasive, ubiquitous, and central to social belonging and cultural participation, there are widening expectations of its availability at all times. This is the case with cars, where mobile Internet use is becoming more commonplace, involving email, browsing, Facebook updates, tweets, apps, Google Maps, and so on.

We can see mobile Internet's use in cars as forming part of wider systems of technology use. Late modern life is underpinned by intensifying forms of automation, sensing technologies, real-time data gathering and analysis, and surveillance [7], especially in cities - infrastructures deeply involved in the reconstruction of place and mobilities [8,9]. These are technologies that remain much more in the background than the heavily advertised options of plugging one's smartphone into cars, yet their implications are highly significant. These kinds of new Internet and mobile media which, in the words of Mimi Sheller, are "further reshaping urbanism and its "technoscapes" and "mediascapes", creating new affordances for people to navigate public places and built environments, generating new forms of urban spatiality, transmediality and public interaction' [10].

Such coupling of the Internet and cars in the global north can be broadly contrasted with the dramatic developments in both technologies in the global south. At present, there is a second great wave of growth occurring in automobile production and consumption internationally, in the emerging economies of India, China [11], Russia, Brazil [12], and other countries in South America [13,14]. The boom in car sales, ownership, and use is directly bound up with the urbanization and modernization of these countries. These are the very countries in which the Internet - especially mobile Internet-is diffusing at a great rate, and is interwoven into social innovations [15], which as yet are under-researched and analysed. 
For instance, it is likely that we could gain a very different picture of mobile Internet and cars (and other kinds of transport), if we consider the distinctive kinds of questions raised by the quite different contexts of use. We might think of rural people who use mobile phone connectivity to arrange meetings at highways with particular forms of transportation (e.g., trucks to pick up crops or rides into urban markets). Already research on mobile communication has highlighted the interactions among markets, mobility, and information, in relation to agricultural, fisheries, and other primary industries [16,17]. There are experiments with village buses asynchronously uploading and downloading data each time they arrive at a Wi-Fi-equipped stop, or a computer and phone equipped travelling rickshaw [18]. It would be interesting to know, for instance, to what extent, mobile Internet is being integrated with the boom in Bus Rapid Transit Systems in global south megacities [19], and how it compares with the integration of public transport with systems of wireless and mobile Internet occurring in various urban and rural settings in the global north [20,21].

Accordingly, in this paper, I consider the new phase of the tandem technologies of cars and mobile - represented by the mobile Internet. My focus is upon vehicular Internet in the countries of the global north - where there is information and research available, a likely result of focus by car manufacturers and perceived demand by consumers. I am acutely aware, however, that the developments in the global south, while probably more resembling "informal economies' at this stage - that is, less subject to organized, clearly articulated systems of production and consumption - are likely to be of greater significance, given the world historical nature of the social transformations in which Internet and cars are deeply involved.

With this caveat, my argument is two-fold: firstly, the advent of mobile Internet in cars bring together new, widely divergent trajectories of Internet, that require urgent critical research and reflection - because they are still rarely considered in mainstream discussions of the Internet and its future. Secondly, such developments indicate a new assembling of the social underway in mobile Internet, to be discerned in the distinctive forms it takes in cars.

Before I proceed to establish this argument and discuss the twinning of cars and mobile Internet, it is important to establish my theoretical framework. My approach is informed by three main schools of thought: the social shaping of technology approach, extended by actor network theory of Bruno Latour, and others [22,23]; mobilities theories, especially those developed by John Urry and Mimi Sheller (already cited here); and cultural studies' work especially the classic "circuit of culture" model developed by Paul du Gay and co-authors in their account of the Sony Walkman [24]. From across these three broad approaches we find a rich body of research on the automobile and its place in society and culture. We also find important work on the Internet, and, from a related yet distinct field, accounts of mobile phones and mobile media. While there have been important discussions of the car's relationship to media and communication (as well as transportation) — especially in the new approaches offered by mobilities thinkers, and diverse discussions of Internet and cars (especially in the scientific and technical literatures), surprisingly systematic critical enquiries into the car and Internet as particular, combined, hybrid systems, or what can be called, after Gilles Deleuze, assemblages [25], have not been forthcoming. So my theoretical framework in this paper aims, in a most preliminary fashion, to underpin an analysis of this conjuncture in which cars and Internet are being joined in ways that are historically and socially significant. 


\section{Cars, Media, Mobiles}

The central place of automobiles, driving, and car culture in many contemporary societies has meant that people spend a great deal of time in cars. Automobiles have a range of meanings for different groups and classes, and have been especially important in consumer culture. Firstly, because people spent more time in cars, important aspects of communication developed in such vehicles in the twentieth century. Moreover, distinctive kinds of communication developed in association with cars. This included: communication whose principal purpose was the co-ordination the movement and flow of cars (traffic lights and signs, for instance); communication between cars and pedestrians; communication between people travelling in the same car; media use in cars (for instance, reading, listening to radios); and communication between people in one car and other cars or places (via, forms of radio communications). Secondly, the appearance of the car changed the meanings of communication in a broad and fundamental sense, as Rod Giblett suggests:

If the telegraph separated communication from transportation, as [James] Carey and others argue, the car rejoined them to produce a mobile communication and transportation device ... The car has power over space and time yet its power is paradoxical ... the car liberates the driver from the private sphere of the home, office or factory into the public sphere of the street, the road or the off-road, at the same time at it captivates the driver in the car's private sphere of mobile indoor space. [26]

Giblett notes the work of various theorists who either see the car and its occupants communicating with the landscape - in terms of receiving sensory impressions from it [27] — or draw attention to the way the car frames the world around it, with Paul Virilio, for one, comparing the windscreen to a cinema screen - each hosting different kinds of moving images [28]. The question of what kind of mobile space the car is, and what its relationship is to questions of the changing nature of private and public spheres, is something famously raised by Raymond Williams in his notion of "mobile privatisation", concerned that - as exemplified in technologies such as cars-people were increasingly living as self-enclosed families or individuals, yet, at the same time, were increasingly mobile [29]. David Morley has explored mobile privatization, noting that, in positive ways, communication technologies can "function as disembedding mechanisms, powerfully enabling individuals (and sometimes whole families or communities) to escape, at least imaginatively, from their geographical locations" [30]. Most pertinently, Mimi Sheller and John Urry have argued that:

Automobility, as currently constituted, fosters, a civil society of hybridized, "car-drivers", accelerates a collapse of movement between the public and the private, generates a new theme and style of political contestation, and points towards a complex interweaving of mobility and communication within the urban infrastructure. [1]

Such considerations regarding cars themselves as communication technologies, and their social implications, are important where we are confronted with contemporary developments and visions regarding mobile Internet in cars.

As two great, modern technologies of mobilities, the car and the mobile phones have been intimately tied together since the inception of vehicular communications [31]. The precursors of the 
mobile phones that we are familiar with (c. 1979-2007) were radio communications installed in car, for instance, in the United States just after World War II. Trunked radiotelephony became a feature of prestige cars from the 1960s onwards. The first commercially available cellular mobile phones were initially envisaged for use in vehicle, not least because of their bulky size and heavy weight. In the second generation Global System for Mobile (GSM) European standard, the assumption that mobile phones were for in-vehicle or vehicle-supported use was no longer relevant, because the technology became steadily smaller and portable. Intriguingly, as mobile phones untethered themselves from cars, seen in the advent of portable, personal cellular telephony, their association found new forms and indeed deepened.

Indeed connections emerged between the norms of new communication practices associated with mobile phones, on the one hand, and the cultural expectations, social functions, and practical uses of cars, on the other. Car and mobile phone manufacturers developed systems to allow phone calls to be made and received in cars, such as mobile car kits, speaker systems, and hands-free dialling and other functions. The popularity of text messaging from the 1990s onwards meant that this new kind of mobile text communication become a largely-undesigned-for part of what people did in cars. The everyday use of mobile phones in cars - sometimes with, and mostly without, car kits and hands-free accessories saw a highly visible public discourse on safety and the dangers of mobile communications in automobiles, and how such risks could be regulated [32-34]. From a social shaping of technology perspective, the controversial issue of safety and mobile phones in car was highly significant. Thus two sorts of technology associated with mobility came together in a very anxious way.

During the 1980s and especially in the 1990s, mobile communication technology was in an intense process of social shaping - or what Latour would see as mutually interdependent redefinition of both the social and the technological. At a popular and theoretical level, there was great debate over the kinds of connection being made among by people using mobile communication, whether the mediated relationships being forged were qualitatively new, and how these redrew the boundaries between public and private spheres. For its part, automobility had already experienced some decades of these kind of social innovations, realignments between private and public, and creation of hybrities of "car-drivers" (as Urry and Sheller put it). The unfolding domestication of mobile phones, following the work of Haddon in particular, could be seen to create a hybrid of phones-cars-drivers - initially through the monstrous challenge posed to safety. In the pedagogy of driver safety, mobile phone use was compared, in its potentially baleful negative effects, to the dangers of driving while drunk. Text messaging while driving was felt to be even more perilous still $[35,36]$. The availability of people for mobile telephony while driving was thus perceived to have such potential social implications that substantial efforts at regulating the risk were required-on interlocking levels of vehicle design (should phones have functions disabled while vehicles are in motion), public education of populations (mass campaigns), policing (creation of indictable offences and fines), and ethics (care of the driver's self) [37]. This first phase of widespread knitting together of the technological systems of the car and that of mobile phones thus involved efforts to proscribe, manage, and dampen opportunities for person-to-person mobile communication.

In the second phase of the suturing of cars and mobiles - with current mobile Internets - the social implications of cars and mobile Internet have much more positive valences. Before we look directly 
this, we need to approach the pre-conditions of this - that is, the much more multifarious technological systems, and their specific histories, that have come together to make this possible.

In the period of the 1990s and early 2000s, in particular, when the mobile phone became a thoroughly global technology (over 5 billion users by 2011, compared with some 2 billion Internet users in the same period), we can point to significant developments occurring in car electronics, and vehicular information and communication technologies. Notably, computers became incorporated in cars for communication and signal processing within the vehicle's own internal systems. By the twenty-first century, these systems included hugely expanded onboard sensors, widespread use of software throughout vehicles, electronic control systems, as well as systems that gathered increasing amounts of data. At the least, the electronic circuitry, the rise in software in cars, the emergence of the automobile as a key site, or node, in the "Internet of things", and so, can be seen as a intensification of the mediation of automobility; if not, amounting to a strong claim, of a new kind of media_-"cars as media". As noted elsewhere in this paper, the infilitration of the car's interior systems by electronic information and communication technologies is at least matched by the growth in the wide area systems of traffic, transportation, and vehicular informatics in which cars operate. That is, cars are not simply driving on a road or highway systems, or reliant on semotic systems of signs, or networks of traffic lights controlled by a control room. Cars are being piloted — autonomously or automatically—in a veritable empire of information and communication, as much as signs.

Information and communication systems for cars, transportation, and mobilities systems have been the subject of much research and development for some decades. However, a new force in car media and communications has come from a different direction, not previously thought to be part of this sphere of technology and its social co-ordinates. I refer here to the growth of household consumer electronic and entertainment devices and "systems". Not only are car owners and passengers expected to possess and use a car radio, but also to desire many other of the media devices that line their homes and offices, and accompany them on the move: CD and DVD music players; DVD and video players; game consoles and devices. Mobile phones have promised to act as a "convergent" device to consolidate different media practices and technologies, and this is a vision that has recurred with smartphoens. Many middle- and upper-class smartphone users expect to port their lifestyle, data, and media, wherever they go. Many hotels now offer iPhone and other smartphones docks, for instance, with cars doing the same. A pioneering instance is the incorporation of Bluetooth into advanced car systems, allowing user's mobile connectivity could translate relatively seamlessly into the car environment. Thus the car could feature as an acoustic relay for telephone calls or enjoyment of one's digital music collection.

The moves of car manufacturers, mobile companies, and consumer electronics and entertainment companies towards imagining and responding to consumers' desires to be able to use mobile media in car now stand to deepen considerably with mobile Internet becoming a prominent feature of these hybrid technological systems. The appearance of mobile Internet in cars, like that of mobile telephony text messaging before it, has also been accompanied by concerns about safety and risk. Interestingly, the realization that mobile Internet use is occurring in cars has formed part of the new, broader concept of "distracted driving". That is, rather than professional, research, and public attention being narrowly fixed on mobile phone use and its dangers to driver safety, there is now an explicit recognition of the 
range of in-vehicle information and communication technologies, including mobile Internet, that enlist the driver in ways that "distract":

Motor vehicle drivers are increasingly using electronic devices while driving for activities such as calling or sending text messages (texting) from cell phones, watching video, and searching the Internet. Automakers are also incorporating electronic devices into standard vehicle design, including dashboard Internet and satellite connections. Because these devices are integrated into everyday life, drivers mistakenly assume they can be used safely while operating a motor vehicle. Despite their dissimilarities, each of the devices distracts a driver's attention (some more than others), posing a highway safety hazard. [38]

Thus safety is an important facet of the way that mobile Internet and cars are being assembled hybrid media and technological system. However, there are others developments underway in mobile Internet and cars, with wide-ranging implications for social transformations.

During the first decade of the twenty-first century, another class of devices developed during the 2000s that also can be seen as portable, media and communications technology: the satellite navigation (satnav) device. Satnavs used global positioning satellite (GPS) technology in conjunction with a database of information taken from street directory publishers to provide in-car navigation for drivers. Initially satnavs were built into cars_ - of the estimated three million satnavs in US car in 2005, half were in-car devices. Within a few years, portable, personal navigation devices, replacing street directories, and potentially integrating with smartphones and PDAs [39]. By 2009, there were some 30 million satnav devices in the US, with over 90 percent of them portable - typically affixed to the dashboard or windscreen [40]. Satnavs are a prosaic yet fascinating instance of the rise of mapping and location technologies. There was strong interest in using the capabilities of GPS, a pervasive network of satellites first established by the military, for civilian, commercial and non-commercial purposes. In addition, in the late 1990s and early 2000s, there were many other efforts to develop and commercialize location-based services, especially capitalizing on the growing ubiquity and popularity of cellular mobile phones - but also their potential for providing usable information on the location of the device and its user. Mobile phones also began to incorporate GPS technology, meaning that there was the possibility of triangulating location through both these satellite position technology and also mobile telecommunications networks. Yet, it was the satnav that become the first widely used in-car mobile data device. Generally used solely for the purpose of navigation, there were some satnav devices designed for cars that sported Internet capability. With the popularity of mobile apps with smartphones, companies like Garmin offered an Opencaching app, and Garmin Mechanic, an app to track car mileage and performance.

A number of mobile phone manufacturers-most prominently perhaps Nokia-made a concerted pitch to take a share of the domestic satnav market. Many drivers and passengers were happy to avail themselves of a suitably equipped mobile phone, which they could also mount in their car if they wished, or simply use as desired, to navigate their journey, rather than incurring the cost-and potentially inconvenience - or purchasing another device. It is fair to say, however, that the moves by the mobile phone vendors to annex the satnav market via software extensions were nowhere near as successful as something else that was neither so obvious nor predictable: the rise and rise of Google maps. 
Google Maps commenced in 2005, with, road maps and multiple directions to destination features following in 2006 [41]. Its companion program, which also works in a browser, is Google Earth, publicly released in mid-2005. Google released a Maps for Mobiles application in 2006, upgraded to Google Maps for Mobile 2.0 in late 2007-which featured a "My Location" capability, which can use the GPS information of a mobile device in addition to software that uses information on the location of the nearest mobile transmitter (as it does similarly with WiFi transmitter information from a database) [42]. In late 2009, Google released its Maps Navigation app exclusively for Android 2.0 phones [43]. Because Google Maps is available for mobiles, it is used by pedestrians, cyclists, and travellers on all manner of transportation as well as cars. Google Maps is also a leading instance of what has been termed the "geospatial web" (or "geoweb"), the merging of geographical information with web browsers, and the collaborative tools that are layered on top of these [44]. Location and mapping technologiesincluding satnavs, Google Maps, geoweb, and what is now being called geomedia [45]—represent a highly significant stage in the complex intermingling of automobiles, mobiles, and media. Debate is underway about the new kinds of relationships between public and private spaces such mobile media entail, and what kinds of mobilities and immobilities, inclusion and exclusion, and new possibilities for connection these entail.

\section{Connected Worlds: Computing and Internet in Cars}

The portability of mobile phones was a key reason why these communication devices became widely used in cars. Other portable media devices have followed, especially digital music and digital video players - with an interaction between the engineering of these into in-car entertainment systems and the docking and articulation of such pervasive media devices with car systems. Either way, the architecture of cars, much like those of cities, has much more conceived around personal, networked media. Shortly I will return to the theme of mobile Internet as a deepening of pervasive media in cars. For the present, however, I wish to take up explicitly the theme of information and communication technology, computing, and Internet as these technologies have been developed for cars.

Over the past three decades, there has been burgeoning interest in information and communication technology in cars. The late 1980s saw the development of a field of inquiry into vehicle navigation and information systems [46]. By 1995, road transport informatics became sufficiently prominent to warrant discussion of the legal and institutional issues they raised [47]. Within a decade, there were a wide range of new technologies deployed in cars, specifically to assist drivers and reduce driver safety and error. As outlined in a 2003 OECD report on technologies for road safety, these included: vehicle-based systems that, for instance, collect data and on-board units that issue warnings or take partial control of the vehicle (for example, detecting alcohol, drowsiness or collecting data on events such as crashes); roadside infrastructure based systems that collect information, or issue warnings and advisories; co-operative systems that combine both vehicle and roadside-based systems; vehicle speed control safety systems [48]. In addition, there existed a range of technologies not directly relevant to driver safety, including: driver information systems, adaptive cruise controls, traffic management and road demand management systems; "non-driving task technologies" such as radios, cassette/CD players; cell phones; computers providing information about various aspects of trips; laptop PCs; printers and faxes; PDAs (personal digital assistants; handheld/pocket PCs); and infotainment [49]. 
There was an intensification underway of ystems of information and communication technologies in vehicles as well as in the road, signalling, and other infrastructures and frameworks of regulation supported them. Much of this "intelligent" car and driving technology is developing along trajectories centring on design and engineering of vehicles and roads, focussing on associated technical, political, and social problematics, rationales, and aims. However, the crowding in the car of "non-driving task technologies" was raising concerns:

The current rate of development of in-car technologies is phenomenal. Much of this development is without links to governmental and car industry projects aiming at safer and more efficient travel. Development of in-car technologies without governmental involvement or integration with existing in-vehicle technologies from car manufacturers may represent development toward increased driver distraction and task load from after market in-vehicle devices. Conversely, it is possible that overregulation by governmental bodies to prevent on-board technologies can lead to a situation where people take a variety of easily available technologies (laptops, cell phones, PDAs) to achieve similar objectives or functions in a less safe manner. It should also be recognized that after-market devices (cell phones, Internet, PDAs, etc.), can be used to convey pre-trip or on-trip dynamic traffic information about incidents, obstructions, road conditions, road work, and other things that can enhance the drivers situational awareness and reduce accident risk. [47]

In particular, the OECD noted that "private companies are developing and promoting the use of such things as fax machines, on-board computers supporting Internet access, games and video/entertainment systems for use in vehicles", recommending that the introduction of such technologies "should be managed by ensuring they are part of national safety plans and strategies" [47].

No doubt, such recommendations by governmental working groups and agencies were wishful thinking in the face of dynamic, disparate technology developments. This was especially the case with early mobile computing and Internet technologies. Just as media gradually populating and becoming a prevalent, prominent part of cars and car cultures, such as mobile phones, digital music and video players, and satnav devices, a similar trend may be observed with computers. The portability of computers, with the invention and popularity of the laptop computers, meant that early adopters using them, especially those travelling for work, were keen to use them. Accessories were devised specifically for computing, such as the "AutoExec" made by the Zeeland, Michigan, company Mobile Office Vehicle. Authors of a 1998 study into use of the car as a mobile office found that:

The number of people using an in-car computer was small, although it is like to rise as more and more companies utilise computers in their business dealings. Current use of computers, mainly laptops, in the mobile office is primarily to store and retrieve data. People waited until they got home or to their office to download or retrieve data ... The use of other mobile computing facilities such as portable modems, fax modems and printers was minimal. [49]

Cars travellers are being urged to use laptops and other media to work from their car, and indeed various groups of works begin to do so [50,51]. We situate these new media work practices in cars as part of a wider phenomenon of mobile office work and travel time-use in the "information age" [52]. 
Fully-fledged, integrated Internet access in cars was much slower to become a reality, despite efforts by a range of information technology companies, scientists, technologists, and designers. In 1999, IBM, Netscape Communications, and Sun Microsystems, for instance, proposed the "network vehicle", a vision for the "future convergence of computers, the communications infrastructure, and the vehicle":

Drivers can use a head-up display projected through their windshield to navigate to their destination or check vehicle functions without taking their eyes off the road. Passengers using individual terminals next to their seats can do even more, including interacting with the Internet, watching television or playing games ... The Network Vehicle also has an integrated cellular phone, Netscape Communicator software for Web browsing and e-mail, a removable personal digital assistant (PDA) and docking station. [53]

It was not really until 2008-2009, that manufacturers offered "genuine' Internet access in cars, with BMW being among the first to lay claim to this distinction [54]. BMW's iDrive system included three TV screens, which included Internet access as well as DVDs and TV [55]. As well as accessing the Internet directly on the iDrive system and screens, BMW also made available wireless Internet functionality in the car, for drivers and passengers to access via an Internet-equipped mobile [56].

A key difficulty BWM faced was providing easy-to-understand and use controls for its rich panopoly of functions. This was something that the "iDrive" system, first devised in 2001, was supposed to address - the name obviously signifying its parallels with Apple's iMac, iTunes, and iPod, and other range of digital devices which had gained strong consumer acceptance. The task of providing good usability in cars, however, is at least as challenging as in other areas of consumer products and services - not least when it comes to Internet, because of the risk to safety faced by drivers grappling with Internet, or being distracted by passengers doing so. BWM emphasized that its Internet only operated when the car was stationary to precisely address such concerns.

It is fair to say, then, that the development of in-car use of computers and Internet has been a slow, complicated affair. As we have seen, initially workers themselves sought to take advantage of the affordances of both laptop computers and cars to work while travelling. The availability of portable modems as well as data storage devices, followed eventually by the development of wireless Internet and mobile data connectivity made the prospect of mobile Internet — as we now know and experience it - possible in cars, as in all kinds of buildings and environments, trains, planes, bicycles, and so on. Yet in-car Internet access provided by dedicated vehicular screens, or inset in the dashboard, or consoles, held little appeal compared to the capabilities of that already well-established car companion and complement - the mobile phone. As well as better data capabilities of mobiles, a likely factor driving adoption and use are the affordances of widely popular applications, especially Facebook and Twitter. However, especially with smartphones, and tablet computers (like the iPad or Samsung Galaxy), there are a range of apps that integrate mobile telephony, messaging, and contacts, with voice and video over Internet protocol (programs like Apple iPhone's Facetime, or third-party programs like Skype or Viber - popular for "free" voice or video calling, and messaging). So there is good reason to suspect that, like text messaging, many passengers and their drivers, are using mobile devices to access Internet in their cars, while on the move as well as being stationary. The extent of this use is unclear at present, and it was outside of the scope of this paper to conduct empirical research regarding this. 
However, the research literature now emerging from the movement to address and counter distracted driving provides some indications that cars are one of the important contexts of use for mobile Internet [57]. The US National Highway Traffic Safety Administration database now includes the following separate fields for attributes of drive-related factor in fatal crashes: cellular telephone present in vehicle; cellular phone in use in vehicle; computer/fax machines/printers; onboard navigation systems [58].

While we do not yet have firm indications of the extent, characteristics, and dialectic between use and non-use of mobile Internet in cars, it is clear that the manufacturers have substantially invested in designing and imagining such a technological future. The idea of car embodying the "Internet on wheels" or "web on wheels" emerges in the plans of companies such as Mercedes Benz, Ford, GM, and Fiat, as early as 2000 [59-62]. When the smartphone emerged as a cardinal technology for the future of the Internet, it was pressed into service again as a handy metaphor for the car of the future. Toyota's Prius - the iconic car for those concerned with climate change, ecology, and reducing emissions — was in the vanguard of such developments:

Several companies have joined together to turn a Toyota Prius into a smartphone on wheels that can be connected to the Internet to retrieve any kind of content. When parked at home, the car can also synchronize with a digital video recorder, to enable viewing of programmes "taped" while on the move. [63]

Dubbed "ng [next generation] Connect", this particular Prius model was aimed as the mass market, rather than the "Connect" product available in just luxury cars: "Tech-savvy youngsters will be able to play computer games with each other, with people in other cars, or with people on the other side of the world" [44]. In a scaled-up version of BMW's iDrive system, the car itself could act as a wireless hotspot. Such ideas take advantage of the advanced computer processing power built into cars already, and combine this with developments in next-generation fixed broadband and mobile networks. In doing so, mobile Internet becomes a way to achieve the long desired integration of the car, and its technological systems, with those of the pervasive technologies and social worlds of home and business.

This "connectedness", which the Internet enables, is presented as remedy for the previous monadic worlds of personal technology:

The world of telematics is vast and ever expanding as we yearn for more of the latest gadgets and as we feel as isolated as Robinson Cruscoe if we leave home without them. Essentially the theory is that our numerous worlds should be connected and interrelated. Walk out the door of your automated home, keep up with your e-mails on your cellphone or PDA as you walk down the driveway and then check your stocks as you climb into the car and head to the office where you are surrounded by more technology, all of which claims to make your life easier. [63]

Explaining Ford's "Sync" communications and entertainment package, jointly developed with Microsoft, the company's President of the Americas explained:

"We define connectivity as a way to keep people moving through their lives — not simply as an on-board computer ... Our approach focuses on connecting people to the information they need, whenever and wherever they need it". [63] 
Such visions of the connected, enhanced quality lifestyle were guiding the plans of Microsoft, whose "Embedded Automobile 7", were also adopted by Fiat and Nissan. Underlying such efforts are the work on standardization of technical systems and infrastructures that can make this possible, not least work on implementation of Internet IPv6, as well as the development of fourth-generation mobile networks $[64,65]$. Yet in addition to this important work of creating the grounds for connection across technological systems, we also find a great deal of effort invested in the social and cultural transformations that make this possible. For instance, the cultural work involved in the 2010 advertising campaign presenting the Ford Fiesta as the exemplary "connected lifestyle" vehicle:

Boasting the tagline "Life's better connected", the TVC features the Fiesta travelling across the city and allowing its driver to connect with her friends and music through BlueTooth and voice control. Orbiting glass spheres carrying the driver's friends as she connects with them visually communicates the car's modern attributes. [66]

The various domains of the driver's life-friendship groups, leisure venues, workplaces, "non-places" [67] of commuting such as roads and bridges - are still represented as distinct through the metaphor of the glass spheres. These distinct spheres are connected, not only through the car's ability to convey the driver to these different places, but through the pervasiveness of the network technologies that bridge them, brought together by the mobile phone.

There is a strange dissonance that arises with the persistence of the social imaginary of the "Internet on wheels", now transmogrified into the "smartphone on wheels". This trope relies on the separation of the car-as-communication-control-centre from the technological systems that underpin it, and provide its conditions of possibility. In effect, it is another kind of "mobile privatization" that has cast a long shadow over modern media and new communication technology. In contradiction to this, it is worth emphasising that communication takes place not just by occupants in cars, and their absent or co-present others; communication also occurs, and connects, the car, the road, and other traffic and intelligent highway systems. Much of the potential and claims around car-based mobile media has to do with traffic management, networked safety systems, automated driving, and other systems, a number of which also depend on the reach and capabilities of cellular networks and real-time connectivity.

\section{Conclusion}

In this paper, I have traced the development of different kinds of information and communication technologies associated with the automobile. These disparate technologies stretch back at least three decades, though their roots are deeper still. We find a gulf in these histories between technology centering on the car and its associated infrastructures and systems ("in-car"; vehicular informatics; road systems; and so on), on the one hand, and technology that follows people into cars, as they become drivers and passengers. The latest of these technologies that has infiltrated the car is mobile Internet. These gulf between these two tendencies — car media, and media in cars - has narrowed. Thus we can point to many crisscrossings of technologies, standards, policies, behaviours, and practices, through which the car is increasingly embedded in the general situation of contemporary networked digital technologies. As I have noted, there are even attempts to annex the "connected car" to developments in convergence culture and the smartphone turn in mobile media. 
However, such an account of mobile Internet in car fails to comprehend the kind of material achievement and modes of connectivity it entails, and indeed fundamentally misconstrues the emergent, distinctively new interfaces being created at the seams of media and transportation histories, and among the infrastructures, objects, and practices they involve. Rather than seeing mobile Internet is cars, it is much more productive, and accurate, to regard it as being stitched together across a range of places that connected bodies and things move through. The specific materiality of communication media in cars is being created through a complex of technological systems, political economies, cultural politics, and the social transformations created along with these. The connectivity that results is often quite provisional [68]; or, rather, it co-exists with significant disconnections, not least those based on money to participate in the respective, if now overlapping, economies of cars and mobile Internet.

The reality is mobile Internet in cars decentres both of these objects. It requires us to identify, make sense of, and analyse a varieties of mobile Internets, that are taking shape as much in the interstices of traffic and vehicle systems, and the capabilities of telecommunications, mobiles, Internet, and mobile networks, and the incidental media flows and practices they now make possible - as they are in the more easily identifiable use of Internet-equipped mobile media devices in cars. This much larger, messier scene means that we have to radically broaden our view of the "telecocoon" of both cars and mobile Internet, to appreciate the new relations being forged between these two technologies of mobilities, and the ecologies of place in which they take shape and form.

\section{References}

1. Sheller, M.; Urry, J. The city and the car. Int. J. Urban Reg. Res. 2000, 24, 737-757.

2. Baym, N.K. Personal Connections in the Digital Age; Polity: Cambridge, UK, 2010.

3. Leung, L.; Fung, A.; Lee, P., Eds. Embedding into Our Lives: New Opportunities and Challenges of the Internet; Chinese University Press: Hong Kong, China, 2009.

4. van't Hof, C.; van Est, R.; Daemen, F. Check In/ Check Out: The Public Space as an Internet of Things; NAi Uitgevers: Rotterdam, The Nederland, 2011.

5. Dourish, P.; Bell, G. Divining A Digital Future: Mess and Mythology in Ubiquitous Computing; MIT Press: Cambridge, MA, USA, 2011.

6. Goggin, G. Global Internets. In Handbook of Global Media Research; Wiley: New York, NY, USA, 2012.

7. Fuchs, C., Boersma, K., Albrechtslund, A., Sandoval, M., Eds. The Internet and Surveillance: The Challenges of Web 2.0 and Social Media; Routledge: New York, NY, USA, 2012.

8. Sheller, M.; Urry, J. Introduction: Mobile Cities, Urban Mobilities. In Mobile Technologies of the City; Routledge: New York, NY, USA, 2009.

9. Varnelis, K., Ed. The Infrastructural City: Networked Ecologies in Los AngelesActar: New York, NY, USA, 2008.

10. Sheller, M. Mobility. Sociopedia.isa. 2011. Available online: http://www.sagepub.net/ isa/resources/pdf/Mobility.pdf (accessed on 15 March 2012).

11. Chin, G.T. China's Automobile Modernization: The Party-State and Multinational Corporations; Palgrave Macmillan: Basingstoke, UK, 2010. 
12. Shapiro, H. Engines of Growth: The State and Transnational Auto Companies in Brazil; Cambridge University Press: Cambridge, UK, 1994.

13. Freyssenet, M., Ed. The Second Automobile Revolution: Trajectories of the World Carmakers in the 21 st Century; Palgrave Macmillan: Basingston, UK, 2009.

14. Fu, X., Soete, L., Eds. The Rise of Technological Power in the South; Palgrave Macmillan: Basingstoke, UK, 2010.

15. Donner, J. Research approaches to mobile use in the developing world: A review of the literature. Inf. Soc. 2008, 24, 140-159.

16. Donner, J.; Gitau, S.; Marsden, G. Exploring mobile-only internet use: results of a training study in urban South Africa, Int. J. Commun. 2011, 5, 574-597.

17. Flores-Roux, E.; Mariscal Avilés, J. Oportunidades y Desafíos de la Ancha Móvil. Available online: http://www.acorn-redecom.org/papers/2011Flores-Roux_Espanol.pdf (accessed on 15 March 2012).

18. Tacchi, J.; Grubb, B. The case of the E-Tuktuk. Media Int. Aust. 2007, 125, 71-82.

19. Schlaikjer, E. Latin America's Bus Rapid Transit Boom Offers Opportunities for the U.S. Available online: http://thecityfix.com/blog/latin-americas-bus-rapid-transit-boom-offers-lessonsfor-the-u-s/ (accessed on 15 March 2012).

20. Hensher, D.; Golob, T.F., Bus Rapid Transit Systems: A Comparative Assessment. Transportation 2008, 35, 501-518.

21. Evens, T.; Schuurman, D.; de Marez, L.; Verleye, G. Forecasting broadband Internet adoption on trains in Belgium. Telemat. Inform. 2010, 27, 10-20.

22. Latour, B. Aramis, or The Love of Technology; MIT Press: Cambridge, MA, USA, 1996

23. Latour, B. Reassembling the Social: An Introduction to Actor-Network-Theory; Clarendon: Oxford, UK, 2005.

24. duGay, P.; Hall, S.; Janes,L.; Mackay, H.; Negus, K. Doing Cultural Studies: The Story of the Sony Walkman; Sage: London, UK, 1997.

25. Bennett, T., Healy, C., Eds. Assembling Culture; Routledge: New York, NY, USA, 2010.

26. Giblett, R. Sublime Communication Technologies; Palgrave: Basingstoke, UK, 2008; pp. 93-94.

27. Sachs, W. For the Love of the Automobile: Looking Back into the History of Our Desires; University of California Press: Berkeley, CA, USA, 1992.

28. Virilio, P. The Lost Dimension; Semiotext(e): New York, NY, USA, 1991.

29. Williams, R. Towards 2000; Chatto and Windus: London, UK, 1983.

30. Morley, D. Home Territories: Media, Mobility and Identity; Routledge: London, UK, 2000; pp. 149-150.

31. Weber, H. Mobile Electronic Media: Mobility History at the Intersection of Transport and Media History. Transfers 2011, 1, 27-51.

32. Redelmeier, D.A.; Tibshirani, R.J. Association between cellular-telephone calls and motor vehicle collisions. N. Engl. J. Med. 1997, 336, 453-458.

33. Goodman, M.; Tijerina, L.; Bents, F.; Wierwille, W. Using cellular telephones in vehicles: Safe or unsafe? Transp. Hum. Factors 1999, 1, 3-42.

34. Crundall, D.; Bains, M.; Chapman, P.; Underwood, G. Regulating conversation while driving: A problem for mobile telephones? Transp. Res. Part F 2005, 8, 197-211. 
35. Hosking, S.; Young, K.; Regan, M. The effects of text messaging on young drivers. Hum. Factor 2009, 51, 582-592.

36. Nemme, H.; White, K. Texting while driving: Psychosocial influences on young people's texting intentions and behaviour. Accid. Anal. Prev. 2010, 42, 1257-1265.

37. Jessop, G. A brief history of mobile telephony: The story of phones and cars. South. Rev. 2006, 38, 43-60.

38. Jacobson, P.; Gostin, L. Reducing distracted driving. JAMA 2010, 303, 1419-1420.

39. The Connected Car. The Economist, June 4, 2009. Available online: http://www.economist.com/node/13725743 (accessed on 19 March 2012).

40. MapQuest Partners with TomTom to Offer a Portable, Personal Navigation Device. Media release. Available online: http://corporate.tomtom.com/releasedetail.cfm? ReleaseID=319545 (accessed on 27 September 2005).

41. Pash, A. Google Maps Multiple Destinations. Available online: http://lifehacker.com/software google-maps/google-maps-multiple-destinations-222183.php (accessed on 15 December 2006).

42. Wikipedia, 'Google Maps'. Available online: http://en.wikipedia.org/w/ index.php?title=Google_Maps\&oldid=435995442 (accessed on 24 June 2011).

43. Lapenta, F. The Infosphere, the Geosphere, and the Mirror: The Geomedia-based Normative Renegotiations of Body and Place. In Mobile Technology and Place; Wilken, R., Goggin, G., Eds.; Routledge: New York, NY, USA, 2012; pp. 213-226.

44. Arrington, M. Google Redefines GPS Navigation Landscape: Google Maps Navigation For Android 2.0. TechCrunch. Available online: http://techcrunch.com/2009/10/28/google-redefinescar-gps-navigation-google-maps-navigation-android/ (accessed on 28 October 2009).

45. Scharl, A., Tochtermann, K., Eds. How Geobrowsers, Social Software and the Web 2.0 Are Shaping the Network Society; Springer: London, UK, 2007.

46. Reekie, D.H.M.; Case, E.R.; Tsai, J. Vehicle navigation \& information systems, Presented at the First Vehicle Navigation and Information Systems Conference (VNIS '89), Toronto, Canada, 11-13 September, 1989.

47. Camus, J.-P.; Fortin, M. Road Transport Informatics: Institutional and Legal Issues; OECD: Paris, France, 1995.

48. OECD. Road Safety: Impact of New Technologies; OECD: Paris, France, 2003.

49. Macht, J. DWT (Driving While Typing). INC 1996, 18, 19.

50. Flyte, M.G. The vehicle as an IT office environment: Ergonomics design requirements for mobile computing. Int. J. Veh. Des. 2000, 23, 329-341.

51. Eost, C.; Flyte, M.G. An investigation into the use of the car as a mobile office. Appl. Ergon. 1998, 29, 383-388.

52. Lyons, G.; Urry, J. Travel time use in the information age. Transp. Res. Part A 2005, 39, 257-276.

53. Lind, R.; Schumacher, R.; Reger, R.; Olney, R.; Yen, H.; Laur, M.; Freeman, R.; The network vehicle-A glimpse into the future of mobile multi-media. IEEE AES Syst. Mag. 1999, 27-28.

54. Smyth, M. Make your car your mobile office. Bus. Day (South Africa), 2009, 1-2.

55. Hagon, T. New BMW 7-series combines gadgets with grace. Available online: http://www.drive.com.au/ (accessed on 14 October 2008). 
56. 'BMW to Launch In-Car Internet Access in Australia'. Available online: http://www.bmw.com.au/com/en/insights/newsandevents/latest-news/in-car-internet-access.html (accessed on 15 March 2012).

57. Lee, I.; Kim, J.; Kim, J. Use contexts for the mobile internet: A longitudinal study monitoring actual use of mobile internet services. Int. J. Hum.-Comput. Interact. 2005, 18, 262-292.

58. National Highway Traffic Safety Administration. Traffic Safety Facts: Research Note; National Highway Traffic Safety Administration: Washington, DC, USA, 2010.

59. Jameel, A.; Stuempfle, M.; Jiang, D.; Fuchs, A. Web on wheels, Computer 1998, 31, 69-76.

60. Kellerer, W.; Bettstetter, C.; Schwingenschlogl, C.; Sties, P. (Auto) mobile communication in a heterogeneous and converged world. Pers. Commun. IEEE 2001, 8, 41-47.

61. Sheller, M. The City and the Car. Available online: http://ideas.repec.org/a/bla/ijurrs/ v24y2000i4p737-757.html (accessed on 15 March 2012).

62. Sheller, M. Bodies, Cybercars and the Production of Automated-Mobilities. Soc. Cult. Geogr. 2008, 8, 175-197.

63. Shillingford, J. Can you believe IT? A smartphone on wheels. Financial Times, 9 December, 2009. Available online: http://www.ft.com/cms/s/0/aa556486-e4c3-11de-96a2-00144feab49a.html (accessed on 20 March 2012).

64. Ernst, T. The information technology era of the vehicle industry. ACM SIGCOMM Comput. Commun. Rev. 2006, 36, 49-52.

65. Gerlo, M.; Kleinrock, L. Vehicular networks and the future of the mobile internet. Comput. Netw. 2011, 55, 457-469.

66. B \& $\mathrm{T}$, 'Ford Fiesta Gets Connected'. Available online: http://www.bandt.com.au/news/ breaking-campaign--ford-fiesta-gets-connected (accessed on 1 November 2010).

67. Augé, M. Non-Places: Introduction to an Anthropology of Supermodernity; Verso: London, UK, 1995.

68. Mackenzie, A. Wirelessness: Radical Empiricism in Network Cultures; MIT Press: Cambridge, MA, USA, 2010.

(C) 2012 by the author; licensee MDPI, Basel, Switzerland. This article is an open access article distributed under the terms and conditions of the Creative Commons Attribution license (http://creativecommons.org/licenses/by/3.0/). 